DOI: $10.20472 /$ IAC.2017.030.020

\author{
JAEHO LEE \\ Gyeongin Nat'I University of Education, Korea, Republic of \\ JUNHYUNG JANG \\ Gajwa Elementary School, Korea, Republic of \\ HYUNKYUNG SHIN \\ Gachon University, Korea, Republic of \\ JAEKWOUN SHIM \\ Korea University, Korea, Republic of \\ DAIYOUNG KWON \\ Korea University, Korea, Republic of
}

\title{
EXPLORING THE COMPONENTS OF CORE COMPETENCIES ON ESTABLISHING THE CONCEPT OF SW GIFTED PERSONS
}

\begin{abstract}
:
In 2016, Korean Ministry of Science, ICT and Future Planning selected 30 Classes for the SW Gifted(CSWG) through public contest. The selected CSWG taught the SW gifted for 100 hours per year. The Korean Government attempt to differentiate the SW gifted education from existing the Computer Science Gifted education. In order to achieve this attempt, it was necessary to establish the identity of the SW gifted education. And the first step of this attempt was the establishment of the concept of SW gifted persons. This study aims to provide reference model for directions and objectives of SW gifted education. In order to achieve the goals introduced above, we conducted the research in the following steps. First, we selected the concept of ICT-based creative talented person as a base model to establish the concept of SW gifted person. The selected base model composed three core competencies which were 'knowledge and technology competencies', 'synthesizing and creativity competencies', and 'personality competencies'. Second, we developed survey tools, like questionnaires, to investigate participant's recognition of SW gifted person. The survey tools was composed of three components: 'computational thinking', 'entrepreneurship', and 'social responsibility'. Each of the components composed seven elements as follows. The components of computational thinking composed 'abstraction', 'problem decomposition', 'algorithms and procedures', 'data collect, analysis, and presentations', 'automation', 'parallelization', and 'simulation'. The components of entrepreneurship composed 'innovativeness', 'insight', 'patent power', 'positive drive', 'morality', 'orientation for the future', 'collaboration capabilities'. The components of social responsibility composed 'the spirit of self-sacrifice', 'a consciousness of social problem', 'social responsibility', 'empathic ability', 'sense of duty', 'social considerations', 'sense of community service'. Third, we developed on-line survey system by using Google functions and surveyed opinion polling. Finally, we analyzed the collected opinion data. To identify what we summarized and synthesized participant's opinions that average values and agreement level by using frequency analysis. Also, in order to compare opinions that average values and agreement level based on whether or not participant's various experiences and competencies we computed $\mathrm{t}$-value, $\mathrm{F}$-value, and $\mathrm{x} 2$ verification.

[This research was supported by Korea Foundation for the Advancement Science \&
\end{abstract}


Creativity(KOFAC)]

\section{Keywords:}

SW gifted person, concept of SW gifted person, SW gifted education

JEL Classification: 129 